\title{
A inserção de imigrantes portugueses na cidade de Campinas-SP: um estudo a partir da nupcialidade entre 1880 e 1920
}

\author{
Lucas C. André^, Ana Silvia V. Scott.
}

\section{Resumo}

A pesquisa busca traçar o perfil sociodemográfico de imigrantes portugueses, através da variável nupcialidade, radicados na cidade de Campinas - São Paulo, entre 1880 e 1920. Um lugar e tempo marcados por grandes mudanças demográficas, políticas e socioeconômicas que apesar de estarem presentes em vasta bibliografia, pouco tratam da temática da nupcialidade, variável importante para a reprodução não só biológica, mas, também, social da população no passado campineiro. Para alcançar esses objetivos, nos valemos da análise do banco de dados informatizado "Eventos Vitais: Campinas 1875-1921", que sistematizou todas atas de casamento do registro civil naquele período.

Palavras-chave:

demografia histórica, imigração portuguesa, nupcialidade.

\section{Introdução}

O escopo do projeto é o estudo da nupcialidade de imigrantes portugueses e suas variáveis e decorrências, na cidade de Campinas - São Paulo, no arco temporal aqui privilegiado, 1880-1920. Naquele período a cidade era reconhecida como um dos principais polos econômicos e urbanos da província/estado, resultado de sua posição central na expansão do complexo cafeeiro paulista. Dessa forma, Campinas tornou-se o destino de parcela importante dos imigrantes que chegavam ao estado e, principalmente, à região oeste. Para apresentar algumas das características específicas da nupcialidade dos imigrantes portugueses que se casaram em Campinas apresentam-se, a seguir, alguns dos resultados obtidos a partir da exploração das informações disponíveis nas atas do registro civil de casamentos sistematizadas no banco de dados utilizado. Buscou-se averiguar se o que afirma Maria Silvia Bassanezi em seus estudos sobre imigrantes em outras regiões do Estado aplica-se ao comportamento dos portugueses em Campinas à época.

\section{Resultados e Discussão}

A principal base empírica para esse estudo foi o banco de dados "Eventos Vitais: Campinas 1875-1921", manuseado através do Software SPSS Statistics, que abre muitas possibilidades para o cruzamento de informações relevantes a esta pesquisa.

Tabela 1. Nacionalidade dos Noivos(as) casados em Campinas 1880-1920

\begin{tabular}{|l|r|r|r|r|r|}
\hline & \multicolumn{3}{|c|}{ Nacionalidade da noiva } & \\
\cline { 2 - 5 } Nacionalidade do noivo & $\begin{array}{c}\text { Não declarada } \\
\text { ou ileaivel }\end{array}$ & Brasileira & Portuquesa & Outras & \multicolumn{1}{c|}{ Total } \\
\hline Não declarada ou ilegivel & 77 & 12 & 1 & 1 & 91 \\
Brasileira & 16 & 6843 & 149 & 587 & 7595 \\
Portuguesa & 6 & 818 & 616 & 149 & 1589 \\
Outras & 31 & 1623 & 57 & 3507 & 5218 \\
Total & 130 & 9296 & 823 & 4244 & 14493 \\
\hline
\end{tabular}

A tabela 1 mostra que havia uma tendência à homogamia por origem entre os casais, isto é, estrangeiros preferiam casar-se entre si, e brasileiros também. Porém, neste caso, houve a exceção dos portugueses que, em sua maioria, buscaram suas noivas entre as brasileiras. Consoante BASSANEZI, isso se deve ao fato de que as portuguesas imigravam com suas famílias para o trabalho na cafeicultura, enquanto que os homens costumavam imigrar sozinhos e em direção aos núcleos urbanos, resultando numa razão de sexo bastante desequilibrada, 0 que indica o peso maior da imigração diferencial masculina entre os portugueses que nos demais grupos. No entanto, os homens brasileiros filhos de portugueses procuravam escolher mulheres de sua mesma origem. Nesse caso, continuava um padrão de homogamia oculta (por origem). Quanto à idade ao casar, observamos que a maioria das mulheres se casava em idades mais precoces que os homens, seguindo o padrão da época. Em Campinas, em torno de $85 \%$ das mulheres casavam-se até os 24 anos, enquanto $75 \%$ dos homens entre 20 e 29 anos. Ainda foi possível perceber que os cônjuges portugueses casavamse com idades médias mais elevadas que os nacionais, embora se casassem mais cedo do que seus conterrâneos que haviam permanecido na terra natal, especialmente ao comparamos os dados do noroeste português.

\section{Conclusões}

Podemos considerar que muitas características dos matrimônios que envolviam um dos nubentes de origem portuguesa realizados em Campinas, eram semelhantes àquelas encontradas em diferentes localidades já estudadas por outros autores, o que possibilitou traçar um perfil dos mesmos, especialmente a escolha por casamentos endogâmicos.

\section{Agradecimentos}

Agradeço a Professora Dra. Maria Silvia Bassanezi, pesquisadora do NEPO/UNICAMP, que gentilmente cedeu o uso do banco de dados "Eventos Vitais: Campinas 1875-1921".

Essa pesquisa foi possível graças ao fomento do $\mathrm{PIBIC/CNPq}$

\footnotetext{
Referências:

BASSANEZI, M. S. Registros paroquiais e civis: Os eventos vitais na reconstituição da história. In: PINSKY, C. B.; LUCA, T. R. (orgs.): O historiador e suas fontes. São Paulo: Ed. Contexto, 2009, p. 141-172.

BASSANEZI, M. S. C. B. As Escolhas Matrimoniais no Velho Oeste Paulista In: VII Encontro Nacional de Estudos Populacionais. 1990. Caxambu-MG. Anais do VII Encontro Nacional de Estudos Populacionais. Belo Horizonte: ABEP, 1990. v.1. p. $241-257$

SCOTT, A. S. V.; TRUZZI, O. M. S. Associativismo beneficente como polo gerador de lusitanidade. Paper apresentado no Seminário Internacional Migrantes Estrangeiros no interior paulista. Inserção, mobilidade e identidade (1880- 1950). Associativismo beneficente como polo gerador de lusitanidade: evidências para o interior paulista. UFSCar, São Carlos, 2017
} 